\title{
EL MOTIVO DEL VIAJE EN LOS AUTOS SACRAMENTALES DE CALDERÓN, I: LOS VIAJES MITOLÓGICOS ${ }^{1}$
}

\author{
IGNACIO ARELLANO \\ GRISO. Universidad de Navarra/Exeter College. \\ University of Oxford
}

\section{RESUMEN}

El artículo examina los aspectos del viaje en cinco autos de argumento mitológico de Calderón, analizando los principales elementos de relato de viaje y su utilización alegórica en el marco del género sacramental. Destaca por su importancia la estructura del viaje en los autos El divino Jasón y Los encantos de la Culpa, sobre la historia de los argonautas y la Odisea respectivamente.

Palabras clave: Calderón, auto sacramental, viaje, mitología.

\section{THE TRAVEL MOTIF IN THE SACRAMENTAL PLAYS OF CALDERÓN, I: THE MYTHOLOGICAL TRAVELS}

\section{ABSTRACT}

The article examines the aspects of the travel in five allegorical plays of Calderón with mythological argument, analyzing the main elements of travel narrative and allegorical use in relation with conventions of the sacramental plays. Especially important is the structure of travel in El divino Jasón and Los encantos de la Culpa organized on the story of the Argonauts and the Odyssey respectively.

Key Words: Calderón, Allegorical plays, Travel, Mithology.

La crítica se ha esforzado en los últimos años en delimitar el género de los libros y relatos de viajes, estableciendo sus coordenadas principales, y estudiando algunos de los textos más relevantes. Baste remitir a los abun-

${ }^{1}$ Este trabajo pertenece al proyecto de autos sacramentales financiado por Subdirección General de Proyectos de Investigación (FFI2008-02319/FILO) cofinanciado por el FEDER. Cuenta también con el patrocinio de TC-12, en el marco del Programa Consolider-Ingenio, CSD2009-00033, del Plan Nacional de Investigación Científica, Desarrollo e Innovación Tecnológica. 
dantes trabajos de Sofía Carrizo Rueda o Luis Alburquerque ${ }^{2}$, quien califica al género de «proteico» y apunta que la cualidad miscelánea suele considerarse comúnmente rasgo característico de esta modalidad textual.

Los autos de Calderón no son, obviamente, relatos de viajes, pero integran de manera constante elementos viajeros — nada extraños si se tiene en cuenta que uno de sus grandes esquemas argumentales es el de la peregrinación o el destierro del homo viator en su vida terrena-, que quizá merezca la pena examinar.

Los viajes de los autos calderonianos pertenecen a cuatro categorías principales, no excluyentes entre sí, de las cuales observaré aquí la primera:

1) viajes cuyo argumento procede de la mitología clásica

2) viajes misionales, en los que el viajero ha de cumplir una determinada tarea, a la que la técnica alegórica confiere siempre un sentido religioso

3) destierros y fugas

4) peregrinaciones propiamente dichas, modalidad que de alguna manera puede englobar a todas, pero que adquiere rasgos muy específicos en algunos casos como el de El año santo de Roma, sobre el jubileo de 1650, o La protestación de la fe, sobre la peregrinación de la reina Cristina de Suecia a Roma para profesar la fe católica.

\footnotetext{
${ }^{2}$ Remito solo a CARRIZO RUEDA, S. M. «¿Existe el género 'relatos de viajes'?». En: Caminería hispánica: Actas del II Congreso internacional de caminería hispánica: III. Caminería literaria e hispanoamericana. Madrid: AACHE, 1996a, pp. 39-44; «Morfología y variantes del relato de viajes». En: Libros de viaje. Murcia: Universidad de Murcia, 1996b, pp. 119-126; Poética del relato de viajes. Kassel: Reichenberger, 1997; «Construcción y recepción de fragmentos de mundo». En: Escrituras del viaje. Buenos Aire: Biblos, 2008, pp. 9-34; ALBURQUERQUE GARCÍA, L. «A propósito de Judíos, Moros y Cristianos: El género relato de viajes en Camilo José Cela». Revista de Literatura, 66.132, 2004, pp. 503-524; «Consideraciones acerca del género «relato de viajes» en la literatura del Siglo de Oro». En: El Siglo de Oro en el nuevo milenio, I. Pamplona: EUNSA, 2005, pp. 129142; «Los libros de viaje como género literario». En: Diez estudios sobre literatura de viajes. Madrid: CSIC, 2006, pp. 67-87; «Algunas notas sobre la consolidación de los relatos de viaje como género literario». En: Ars bene docendi. Homenaje al profesor Kurt Spang. Pamplona: EUNSA, 2009, pp. 27-34; «Of travels and travellers: History of a literary genre». En: East and West. Exploring cultural Manifestations. New Delhi / Mumbai: Somaiya Publications, 2010, pp. 201-216. Ver también sobre cuestiones genéricas y otros aspectos del relato de viaje que no tocaré ahora, REGALÉS SERNA, A. «Para una crítica de la categoría 'literatura de viajes'». Castilla, 5, 1983, pp. 63-85; POPEANGA, E. «El viaje iniciático: las peregrinaciones, itinerarios, guías y relatos». Revista de filología románica, Anejo 1, 1991, p. 27-371; WOLFZETTEL, F. «Relato de viaje y estructura mítica». En: Los libros de viaje: realidad vivida y género literario, Romero Tobar, Leonardo (ed.). Madrid: Akal, 2005, pp. 10-25.
} 
En todas las categorías resulta privilegiado el modelo del viaje marítimo en el cual se inserta la imagen de la nave del mercader ${ }^{3}$, tipo a su vez de la nave de la Iglesia y de la Eucaristía, como se verá con más detalle a continuación.

Dejando aparte algunos casos menos significativos para nuestro asunto (como Psiquis y Cupido), hay cinco autos de argumento mitológico que implican importantes viajes de los héroes protagonistas.

En El divino Orfeo el tema del viaje es complementario ${ }^{4}$ del rasgo esencial que establece el paralelismo entre la figura mitológica y Cristo, asimilación que explora sobre todo la simbología de la cítara como imagen de la cruz, y la del canto de Orfeo como palabra de Dios, Verbo redentor.

En la tradición previa algunos expositores, como Clemente de Alejandría, contraponen antitéticamente a Orfeo con Cristo, precisamente porque aquel, como otros músicos del paganismo, sirvió con sus cantos a los demonios, mientras que el Verbo divino introduce el verdadero cántico salvador:

sólo Él domesticó a los más terribles animales que hubo nunca, ¡a los hombres! A los irreflexivos, que son como aves, a los mentirosos como reptiles, a los iracundos como leones, a los voluptuosos como cerdos, a los ladrones como lobos, y a los necios como piedra o madera. Incluso más insensible que las piedras es el hombre que se encuentra sumergido en la ignorancia ${ }^{5}$.

Pero el paralelismo permite igualmente mediante la lectura alegórica la identificación del músico de Tracia con Cristo, el divino Orfeo. Y en este sentido es fundamental el viaje de ambos a los infiernos.

Sin embargo, antes de que el divino Orfeo descienda al seno de Abraham, otro viajero, también imprescindible en los autos de Calderón, apa-

${ }^{3}$ La fuente de este motivo es Proverbios, 31 , 14, en la alabanza de la mujer fuerte «Facta est quasi navis institoris / de longe portans panem suum». La nave del mercader, a la que Calderón dedica un auto completo, es imagen de la Iglesia, del reino de los cielos y del Sacramento de la Eucaristía... Ana Suárez («El viaje marítimo del mercader en los autos de Calderón». Anuario calderoniano, 4, 2011, en prensa) ha estudiado recientemente este motivo en los autos de Calderón y remito a su comentario para más detalles. Para la imagen general de la nave de la Iglesia ver RAHNER, H. L'ecclesiologia dei Padri. Roma: Edizioni Paoline, 1971; o DANIÉLOU, J. Los símbolos cristianos primitivos. Munuera, C. (tr.). Bilbao: Ega, 1993, cap. IV, «La nave de la Iglesia».

${ }^{4}$ Como indica Carrizo Rueda, S. M. «Construcción y recepción...», p. 12: «no todo «relato de viaje» llega a constituir un libro. Hay muchos casos en que queda acotado a fragmento de una obra mayor». A estos pertenecerían los tres autos primeros que comentaré, mientras que El divino Jasón y Los encantos de la Culpa serían autos configurados enteramente sobre el paradigma del viaje.

${ }^{5}$ Clemente de Alejandría, Protréptico, cap. I, 3, 4, p. 43. Citado por Duarte en su espléndida edición de El divino Orfeo, de cuyo prólogo extraigo los principales detalles de mi comentario (El divino Orfeo. Duarte, Enrique (ed.). Pamplona / Kassel: Universidad de Navarra / Reichenberger, 1999). Duarte estudia muchos aspectos del paralelo Orfeo-Cristo, con abundante documentación. Hay dos versiones del auto; si no indico otra cosa me refiero a la versión final, de 1663, que cito siempre por la ed. de Duarte. 
rece en escena: es el Príncipe de las tinieblas, que navega por las aguas del Leteo como un corsario en busca de presas, un pirata errante, cuya nave diabólica, pilotada por la Envidia, va pintada de negro y adornada con áspides por insignia:

En el carro primero, que será una nave negra y negras sus flámulas, banderolas, jarcias y gallardetes, pintadas de áspides por armas y dando vuelta, se ven en su popa el Príncipe de las tinieblas y la Envidia con bandas, plumas y bengalas negras.

\begin{tabular}{|c|c|}
\hline CIP & $\begin{array}{l}\text { Ya que sulcar me veo } \\
\text { sobre las negras ondas del Leteo, } \\
\text { imaginado río } \\
\text { que entre el caos y el abismo imperio mío, } \\
\text { corre veloz, por cuyas pardas nieblas } \\
\text { el gran Príncipe soy de las tinieblas, } \\
\text { ya que sulcar, digo otra vez, me veo } \\
\text { sobre las negras ondas del Leteo, } \\
\text { a quien por lo letal otro sentido } \\
\text { ha de llamar el río del olvido, } \\
\text { dé un bordo y otro esta supuesta nave, } \\
\text { no del Austro impelida, que süavecorre del mediodía, } \\
\text { sino del Aquilón que el Norte envía. (vv. 1-14) }\end{array}$ \\
\hline
\end{tabular}

Esta nave, como todas las diabólicas de los autos, está impulsada por el Aquilón ${ }^{6}$, mientras que las naves de la Iglesia serán empujadas por el viento Austro, en una referencia precisa a la casa de Austria, defensora de la fe, a través de un pasaje de la profecía de Habacuc, 3, 3 («Deus ab Austro veniet») $)^{7}$.

Cuando la Naturaleza humana come la manzana envenenada, cae sin sentido y el Príncipe de las tinieblas la arrebata para llevarla al infierno;

\footnotetext{
${ }^{6}$ El norte simboliza el origen del mal, donde coloca su trono el demonio, del lado del aquilón 'viento del norte': es el lugar de la oscuridad de donde vienen reyes destructores en diversos pasajes de la Biblia: Daniel, 11, 8: «Y aun a los dioses de ellos, sus imágenes fundidas y sus objetos preciosos de plata y de oro, llevará cautivos a Egipto; y por años se mantendrá él contra el rey del norte»; 11, 11: «se enfurecerá el rey del austro y luchará con el rey del aquilón»; etc. Lucifer piensa colocar su trono en el lado del aquilón: ver Isaías, 14, 11-14: «Tú que decías en tu corazón: Subiré al cielo; en lo alto, junto a las estrellas de Dios, levantaré mi trono, y en el monte del testimonio me sentaré, a los lados del aquilón». El rey del aquilón representa al demonio y del aquilón viene todo mal. Ver ARELLANO, I. Diccionario de los autos sacramentales de Calderón. Kassel: Reichenberger, 2000, s. v.

${ }^{7}$ Versión de la Vulgata, que es a la que remite siempre Calderón. Para el uso que hace Calderón de este texto mesiánico como referencia a la Casa de Austria, ver RULL, E. «Hacia la delimitación de una teoría político-teológica en el teatro de Calderón». En: Calderón, Actas del Congreso Internacional sobre Calderón y el teatro español del Siglo de Oro. Luciano García Lorenzo (ed.). Madrid: CSIC, 1983, vol. II, pp. 759-767; «Función teológico política de la loa». Notas y estudios filológicos. Pamplona: UNED, 2, 1985, pp. 33-46; y en Apuntes sobre la loa sacramental y cortesana. Loas completas de Bances Candamo. Arellano, Ignacio; Spang, Kurt y Pinillos, María Carmen (ed.). Kassel: Reichenberger, 1994, pp. 25-35.
} 
de allí la rescatará el divino Orfeo, como el del mito pagano sacó del Hades a su esposa Eurídice, con la diferencia de que el divino rescatará a su esposa para siempre.

Esta bajada de Cristo a los infiernos se recoge en el Credo de los Apóstoles y en numerosas referencias de los evangelios apócrifos. Como recuerda Duarte en su introducción al auto, San Clemente de Alejandría, Orígenes y San Agustín comentaron el episodio, que Calderón utilizó en otros autos sacramentales (El socorro general, La semilla y la cizaña, El verdadero Dios Pan, El valle de la Zarzuela, El laberinto del mundo, La cura y la enfermedad...), aunque «en ninguno este descenso establece una relación más coherente entre la parte historial de la alegoría y su sentido místico» ${ }^{8}$. En la versión segunda del auto, Calderón elabora con más cuidado la adaptación del mito clásico, ya que Orfeo llega primero al Limbo o seno de Abraham9, para rescatar a los justos muertos antes de la redención. En la versión inicial, de 1634, el lugar al que viaja Orfeo todavía conservaba su nomenclatura clásica (Cocito, Tártaro o Báratro).

La identificación de Orfeo con Cristo, a partir del viaje o descenso a los infiernos, se desarrolla desde el siglo XII, con la versión más relevante en el Ovide Moralisé, (ss. XIII-XIV) que ofrece correspondencias alegóricas para cada detalle de las Metamorfosis:

Las serpientes que les suplantan son los diablos, quienes atentaron la primera vez en el paraíso deleitable, cuando con su tentación les introdujo el mal deseo de comer la manzana envenenada [...] Es el pie envenenado que toda criatura humana tiene por el que todo el género humano fue metido en el tormento infernal. De estos dolores formados, Dios, que predestinó al alma para ser su amiga y esposa y para librarla, quiso bajar del cielo a la tierra y descender a la cámara oscura del infierno para sacar a la Naturaleza Humana de la prisión infernal y ponerla a salvo ${ }^{10}$.

En el auto se ofrecen algunos detalles (decorado verbal fundamentalmente) del territorio subterráneo por el que debe transitar Orfeo - es una senda llena de abrojos, que lleva a la ribera del Leteo, poblada de víboras-, pero no se detiene especialmente en una descripción de los lugares, rasgo que sería característico de los relatos de viajes ${ }^{11}$.

\footnotetext{
${ }^{8}$ DUARTE, E. (ed.). Introducción a Calderón de la Barca, P., El divino Orfeo. Pamplona / Kassel: Universidad de Navarra / Reichenberger, 1999, p. 58.

9 imbo o limbo: «Lugar subterráneo, do no llegan los rayos del sol [...] Pero en sinificación particular, cerca de nuestra Fe Católica, llamamos limbo aquella parte del infierno que retuvo en sí los santos padres antes de la redención del linaje humano» (COVARRUBIAS, S. de. Tesoro de la lengua castellana. Arellano, Ignacio y Zafra, Rafael (ed.). Madrid: Iberoamericana, 2006). Ver ARELLANO, I. Diccionario de los autos sacramentales de Calderón, s. v. imbo.

${ }^{10}$ Boer, Ovide moralisé, vol. IV, libro X, vv. 466-485. Cito por Duarte, Introducción a Calderón de la Barca, P., El divino Orfeo, p. 23.

${ }^{11}$ Carrizo Rueda («Construcción y recepción...», p. 16) apunta el «papel preponderante que cumple la descripción en el discurso propio de un relato de viaje». Alburquerque («A propósito de Judíos, Moros y Cristianos...») lo señala también como rasgo definitorio.
} 
Una vez rescatada la Naturaleza, el divino Orfeo se asegura de su salvación al trasladarla en la nave de la vida, protegida por los Sacramentos:

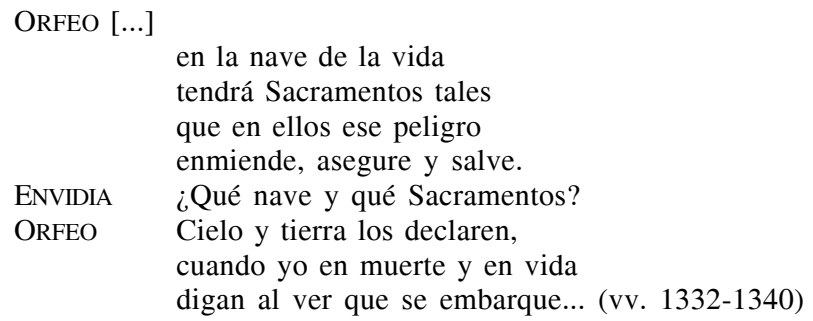

Esta nave de la vida es precisamente la nave de la Iglesia, que en oposición de la primera, aparece «dorada, con flámulas y gallardetes blancos y encarnados, pintados en ellos el Sacramento y por fanal un Cáliz grande con una Hostia» ${ }^{12}$. En ella emprende la Naturaleza un viaje nuevo hacia el reino de Dios, entre los saludos de la música que le desea un buen pasaje, según fórmula habitual para las despedidas de los viajes por mar:

$\begin{array}{ll}\text { ToDos Y MúsICA } & \text { A la nave de la vida } \\ \text { Coro } 1^{\circ} & \begin{array}{l}\text { La Naturaleza pase, } \\ \text { Pues la nave de la Iglesia } \\ \text { es de la vida la nave. }\end{array} \\ \text { Coro } 1^{\circ} & \begin{array}{l}\text { Buen viaje. } \\ \text { Coro } 2^{\circ}\end{array} \\ \text { Buen pasaje. (vv. 1341-1345) }\end{array}$

En su estudio del motivo de la nave del mercader recuerda Ana Suárez que estas naves eucarísticas tienen notables paralelos en la iconografía visual de la época, entre otros la importante ilustración de la Psalmodia eucharistica de Melchor Prieto ${ }^{13}$, cuya lámina 5 representa exactamente la carabela eucarística, defendida por siete cañones, que son los sacramentos, y con otras muchas figuras alegóricas, imagen que encontraremos adaptada en numerosos autos calderonianos, como El divino Jasón.

Naves semejantes transportan a los protagonistas de El laberinto del mundo, que tiene por argumento la conocida historia del laberinto de Creta y el Minotauro. En la versión sacramental el Hombre ha de ser rescatado por Teseo, imagen del Redentor.

${ }^{12}$ CALDERÓN, El divino Orfeo, p. 301.

${ }^{13}$ La carabela de la Psalmodia eucharistica lleva en su borda el texto de Proverbios, 31, 14, alabanza de la mujer fuerte que se compara a la «navis institoris / de longe portans panem suum». La ilustración puede verse en los fondos digitalizados de la Universidad de Sevilla:

<http://fondosdigitales.us.es/media/books/717/717_236779_198.jpeg> [Consulta el 19 de mayo de 2011]. 
Aquí es la nave del Furor la que abre la acción del auto, una galera —navío de forzados - negra, con dragones y serpientes, en la que rema cautivo el Hombre, bajo la vigilancia de Envidia y Malicia:

Descúbrese una galera negra sobre ondas de llamas, pintados sus gallardetes de dragones, y en su proa una serpiente; y en la popa estará el Furor; en el árbol mayor la Envidia, y en un remo el Hombre, de cautivo; en otro la Malicia, y dos forzados a cada lado...

FUROR Amáinese la vela y sin las alas con que nada o vuela este neblí marítimo del viento, boreal delfín del húmedo elemento, al impulso no más del vuelo trate vencer las iras de uno y otro embate con que el aire y el mar nos hacen guerra hasta tomar el puerto en cuya tierra, cierta la entrada, incierta la salida, el laberinto yace de la vida... ${ }^{14}$

En su viaje fatal, la galera se dirige, en efecto, hacia el laberinto, para entregar al Hombre a la voracidad del minotauro que habita en su centro. Tormenta y laberinto significan los peligros y tribulaciones de la vida, como recuerda el mismo Hombre ( $\mathrm{Si}$ en sagradas lecciones / tal vez las aguas son tribulaciones»), aludiendo a textos como los Salmos, y otros pasajes de la Biblia ${ }^{15}$, mientras que el mar del mundo es símbolo muy desarrollado en los Padres y concentra todas las amenazas a la Iglesia.

Para los fundamentos de esta moralidad es útil la comparación con el capítulo pertinente de Pérez de Moya en la Filosofía secreta ${ }^{16}$ :

la reina Pasifa [...] estando ausente su marido Minos, como Ovidio escribe [Metamorfosis, lib. VIII] se enamoró de aquel toro hermoso que Minos dejó de sacrificar, y para tener cópula con él, se metió en una vaca de madera que hizo Dédalo, singular arquitecto, labrada tan al natural y cubierta con una piel de vaca que parecía viva, y así se hizo preñada y parió una criatura que el medio cuerpo de la cintura arriba era hombre y lo demás de toro. Minos, cuando lo supo, hízolo

${ }^{14}$ Cito por la ed. de Valbuena, en CALDERÓN. Obras completas, Autos. Vol. III. Madrid: Aguilar, 1987, p. 1559.

${ }^{15}$ Ver, por ejemplo, Salmos, 17, 17 («Entonces alargome el Señor desde lo alto su mano, y me asió, y sacome de la inundación de tantas aguas»); 31, 6-7 («Y ciertamente que en la inundación de copiosas aguas no llegarán estas a su persona. Tú eres mi asilo en la tribulación, que me tiene cercado»); 68, 15-16 («líbrame de aquellos que me aborrecen, y del profundo de las aguas. No me anegue esta tempestad, ni me trague el abismo del mar»), etc. Ver ARELlANO, I. Diccionario de los autos sacramentales de Calderón, s. v. aguas, símbolo de las tribulaciones.

${ }^{16}$ PÉREZ DE MOYA, J. Filosofía secreta, Gómez de Baquero, Eduardo (ed.). Madrid: Los clásicos olvidados, 1928, lib. IV, cap. 26 «De Minos y laberinto de Creta, y del Minotauro y Pasifa», II, pp. 145 y ss. 
esconder de manera que nunca pareciese, y para esto mandó a Dédalo hiciese una casa de madera, de maravillosa grandeza, muy tenebrosa y de muchos apartamientos y enredos de manera que el que dentro una vez entrase no supiese por dónde salir [...] En este lugar encerraron aquella horrenda criatura, nombrada Minotauro, que su sustento era carne humana [...] Por este laberinto quisieron los antiguos declarar ser la vida del hombre intrincada e impedida con muchos desasosiegos, que de unos menores nacen otros mayores. O el mundo lleno de engaños y desventuras, adonde los hombres andan metidos, sin saber acertar la salida o sus daños, enredados en tantas esperanzas vanas, atados en contentamientos que no hartan, olvidados de sí, embebidos en sus vicios, aficionados a su perdición, finalmente rendidos a sus desenfrenados apetitos.

Por Teseo es entendido el hombre perfecto que sigue el hilo del conocimiento de sí mismo; este tal sale del peligroso laberinto, el cual, no soltándole jamás de la mano, entiende que el cuerpo es mortal y transitorio, y el alma inmortal y eterna, criada para el cielo, y que lo de allá es su tierra y esto de acá es destierro; y con este conocimiento de sí, vencido el terrible Minotauro, que es su propia y desordenada concupiscencia, sale del mundo con maravillosa vitoria.

En otro modo Pasifa, hija del sol, es nuestra alma, hija del sol verdadero, que es Dios, que aunque está casada con la razón que le ha de guardar siempre para que no resbale y dé consigo en los deleites que la apartan del camino derecho, todavía tiene a Venus por enemiga [...] El rodeo inexplicable de las calles del laberinto significa que el que una vez se hubiere entregado a cosas ilegítimas, no se puede después desenredar sin gran dificultad y sin grande artificio de Dédalo, consejero ingenioso...

La interpretación moral del laberinto puede verse también en los repertorios emblemáticos ${ }^{17}$, como el de la Morosophie de Guillaume de La Perrière, en donde aparece un hombre en el centro de un laberinto del que no puede salir, con la glosa:
En volupté facilemente on entre, mais en sort à grand difficulté,
par trop vouloir obeir à son ventre,
l' on est pire en toute faculté.
Ce beau propos avons pour resulté,
su labyrinthe auquel facilement
l'on peut entrer, mais si parfondement, on est dedans, l'issue est difficile.

Desde el punto de vista descriptivo y argumental, el texto evoca los peligros de la navegación, función literaria frecuente en todos los géneros del Siglo de Oro ${ }^{18}$.

Suárez ha comentado con sinderésis la composición dramática de las dos naves en El laberinto del mundo, recogiendo los detalles más significativos:

17 Para documentación emblemática del laberinto ver HENKEL, A.; SCHÖNE, A. Emblemata: Stuttgart, Metzler, 1976, cols. 1200-1202, donde se recoge el de La Perrière.

${ }^{18}$ Para el motivo particular de la tormenta en la literatura del Siglo de Oro ver FERNÁNDEZ MOSQUERA, S. La tormenta en el Siglo de Oro. Variaciones funcionales de un tópico. Madrid / Frankfurt am Main: Iberoamericana / Vervuert, 2006. 
Las palabras iniciales de Furor declaran su aspecto aterrador y apocalíptico («bestia de la mar», «monstruo»), opuesto a la otra nave que aparece después, casi impresionista, «sobre nubarrones azules y flámulas encarnadas, con Hostias y Cálices», en donde está el galán Theos en la popa y la Caridad en el árbol mayor, mientras la Inocencia va en la proa. Esta nave, «que nadar y volar a un tiempo sabe», orientada también por una estrella de luz, solo comparable al sol, se presenta con sus más elevadas cualidades de luz que muestran la belleza exterior e interior («intacta, pura, limpia, clara y bella») mientras la galera negra aparece como guardiana del abismo. Su procedencia también es opuesta: la negra viene del Poniente (equivalente a ocaso y relacionada con la muerte) mientras la blanca llega del Oriente (nacimiento, aurora, otro mundo) impulsada por el Austro. La realidad solar queda transmutada para representar los dos extremos de la existencia, el principio y el fin, apoyada por dos vientos que cumplen asimismo la función de dirigir hacia el bien o hacia el mal la nave de la existencia.

En El laberinto del mundo se reconocen muchos elementos propios de los relatos de viajes, aunque la estructura básica del argumento no se apoye centralmente en ese motivo: un peregrino aventurero que viene el mundo «a buscar altas empresas» (p. 1565), la llegada a una tierra extraña en la que lloran y cantan, y en la que se oyen raras músicas, noticias de esa tierra incógnita, la amenaza del monstruo prodigioso, la descripción del laberinto, cuya «fábrica es tan oscura, / tan pavorosa y funesta, / que aun para espirar no tiene / más claraboya que el Etna» (p. 1567), etc.

Tampoco en Andrómeda y Perseo el viaje es nuclear en el argumento mitológico, pero se integra en él con cierta relevancia para la configuración del héroe. Señala Ruano en su estudio del auto ${ }^{19}$ :

Era fácil convertir a Andrómeda en un símbolo de la Naturaleza Humana salvada por Jesucristo. Perseo, su paladín, es naturalmente el Hijo de Dios, que, a través de su intercesión, logra librarla del monstruo.

Acierta Ruano al calificar a Perseo/Cristo de paladín de Andrómeda, pues según explica el mismo protagonista, viaja por el mundo en busca de aventuras y con el objetivo de favorecer a los necesitados, según el modelo del caballero andante:

$$
\begin{aligned}
& \text { a causa } \\
& \text { de que nunca pude ocioso } \\
& \text { estar, quise que mis hechos } \\
& \text { - para llegar más airoso, } \\
& \text { cuando a declararme llegue--, } \\
& \text { mi fama hiciese notorios } \\
& \text { a todo el orbe. Y así, } \\
& \text { con los azules rebozos, } \\
& \text { que a imitación son de nubes }
\end{aligned}
$$

${ }^{19}$ RUANO DE LA HAZA, J. M. Introducción a Calderón de la Barca, P. Andrómeda y Perseo. Ruano de la Haza, J. M. (ed.). Pamplona / Kassel: Universidad de Navarra / Reichenberger, 1995, p. 30. 


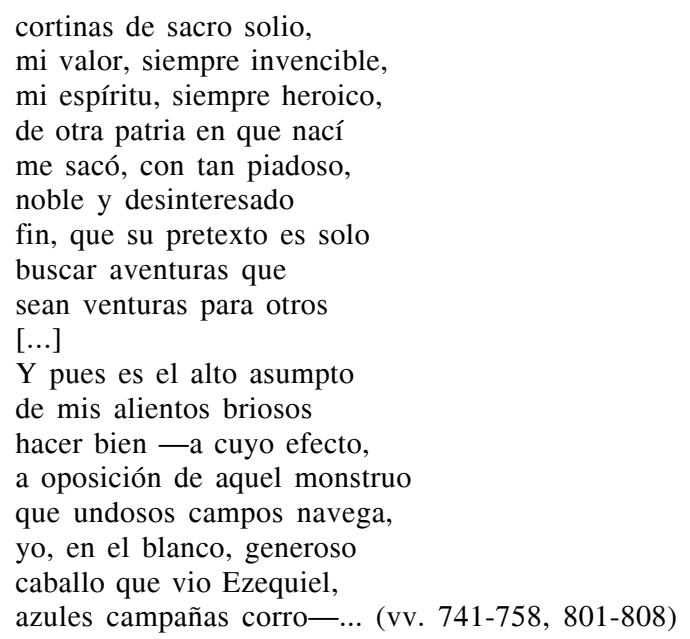

Medusa no conoce a este caballero extranjero que procede de un país en el que no existe la culpa, y que acabará con el dragón infernal que pretende devorar a Andrómeda, quien ha invocado el auxilio de Perseo, tras arrepentirse de haber pecado comiendo la manzana tóxica de la tentación.

En el desenlace Perseo vuelve a confirmar el modelo caballeresco que lo configura, y que incluye el viaje en busca de aventuras, viaje que lo lleva a recorrer todo el mundo deshaciendo agravios, como un don Quijote a lo divino:

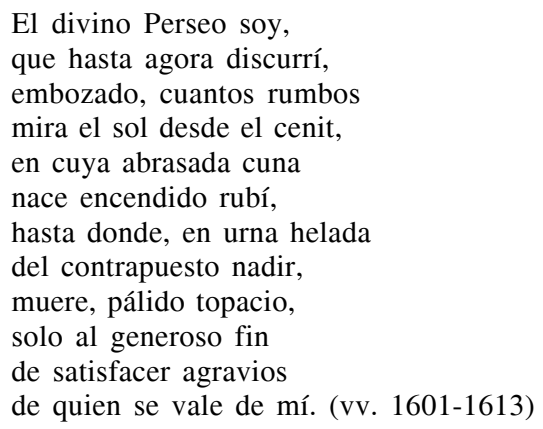

Los dos autos mitológicos restantes que me importa considerar aquí estriban su argumento precisamente en el esquema del viaje, que ordena todos los episodios de la acción. En ellos la estructura básica es la de la aventura y el periplo maravilloso, que lleva a tierras extrañas (islas sobre todo) donde hay objetos mágicos y obstáculos extraordinarios, que debe vencer el héroe épico con ingenio y valor. Las descripciones de los navíos, itinerarios, paisajes, edificios y jardines alcanzan en estas dos piezas un 
rango protagonista, según fórmulas habituales en el género (libro o relato) del viaje.

El divino Jasón, auto temprano, presenta la redención humana en clave alegórica a través de la historia de los argonautas y su expedición en busca del vellocino de oro a la Cólquida ${ }^{20}$. A cada elemento de la leyenda mitológica corresponde con bastante rigor otro elemento en el doble plano simbólico religioso: así Jasón es Cristo, los argonautas (doce) representan a los apóstoles, el vellocino de oro es el alma humana corrompida por el pecado original (a través de la imagen evangélica de la oveja perdida), guardada por los dragones mitológicos que representan los vicios y pecados, las fuerzas del mal, que serán doblegadas por Jasón, etc.

En el desarrollo del argumento se suceden las peripecias de la trama, a cuya lectura alegórica apuntan numerosos detalles: Jasón pide a Argos que construya una nave capaz de triunfar «de todos los elementos» e invita, para que participen en la empresa, a Hércules y Teseo, los cuales aceptan con entusiasmo; declara la intención de conquista; en su isla (cambio de lugar de la acción) Idolatría y Medea dialogan sobre la extraña melancolía de ésta; el Rey (figura alegórica del mundo y sus vanidades), Medea (Gentilidad) e Idolatría comentan la presencia de la portentosa nave, a la que Idolatría amenaza con su total destrucción...

Tras una serie de episodios Teseo conquista el vellocino, mientras la Idolatría, desesperada, desafía a la «católica nave» de los argonautas triunfantes y cuenta la historia de su primitiva rebelión y derrota frente a Dios, que se repite ahora frente al cordero, el cáliz y la hostia que aparecen encima del árbol; la apoteosis triunfal contrapone la glorificación de Jasón al hundimiento en el profundo de la Idolatría con ruido de cohetes tronadores y llamas.

La empresa de Jasón y los argonautas consiste, pues, en un viaje de búsqueda y rescate a través de las aguas del mundo, obstáculos que pueden contrastar pero no hundir al navío Argos (nave de la Iglesia). El Argos se describe metafóricamente, nada más abrirse la acción, como una sirena que no tiene medio cuerpo de pez o ave (vv. 10 y ss.): la metáfora se relaciona con el motivo mitológico de las sirenas que atraían a los navegantes hacia su perdición, pero esta sirena, despojada de su elemento simbólico

\footnotetext{
${ }^{20}$ La leyenda de los argonautas es muy antigua, y la recogen numerosos autores: Homero, Píndaro, Apolonio de Rodas, Eurípides, etc. Jasón emprendió la búsqueda del vellocino de oro, llevado por Frixas a la Cólquida, acompañado de sus argonautas, así llamados por el nombre de su nave, Argos. La nave fue bautizada, según la mayoría de las versiones, con el nombre de su constructor, el argonauta Argos. Entre los argonautas mitológicos figuraban Hércules, Orfeo, Cástor y Pólux, Cetes, Euritos, etc., muchos de ellos héroes hijos de dioses. Más detalles sobre la expedición de los argonautas se pueden ver, por ejemplo, en el Dictionnaire des antiquités grecques et romaines, Daremberg, Charles y Saglio, Edmond (dir.). Paris: Hachette, s. a.
} 
negativo (la parte animalesca, expresión del mal y los bajos instintos) viene a significar lo contrario que las sirenas del mito pagano: es lo que llamaría Gracián una agudeza de disonancia que invierte la función del objeto (sirenas) sobre el que actúa. A pesar de no tener medio cuerpo de pez ni de ave, la sirena-nave de Jasón triunfará de los elementos «ya nadando» (lo que corresponde al pez), ya «volando» (lo que corresponde al ave, cfr. v. 14), y otras metáforas en torno a este mismo motivo insistirán en la ingeniosa mezcla o trueque de atributos, muy conocida en la expresión gongorina y calderoniana: así, la nave será también «águila» (v. 51, 386, 1070), «celeste pájaro» (v. 245) o «neblí de las aguas» (vv. 1062-63), referencias todas a su velocidad y movimiento.

La dimensión alegórica de la nave se explicita en el texto (vv. 401 y ss.), en la ticoscopia alegórica puesta en boca de la Idolatría:

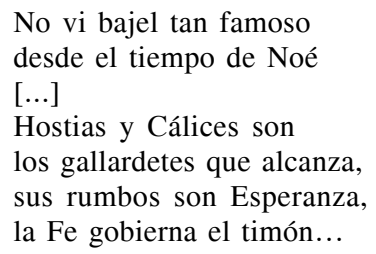

etc.

Se enumeran también los obstáculos del viaje, que convierten la empresa de los argonautas en una difícil aventura, cuyos riesgos no detienen su misión, a la que se dirigen

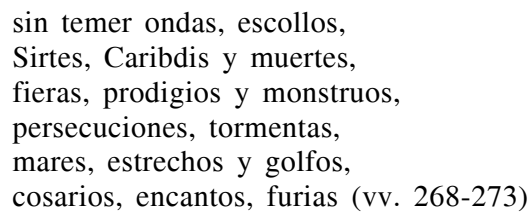

La nave es en sí misma maravillosa: según la describe Medea, navega en medio de una tormenta, protegida por un milagroso globo transparente que la protege:

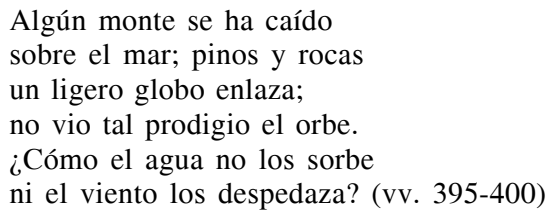

La descripción de Medea alude indudablemente a un elemento prodigioso, un globo ligero (sutil, transparente, a través del cual se ve la nave) que rodea al Argos, creando un espacio aislado, protector de la cólera del 
mar y la tormenta. Es un espacio relacionado con el motivo artístico de los nimbos, globos y aureolas transparentes, que se adaptan del arte oriental en el Renacimiento y cuya figuración en el auto se encomienda a la palabra $^{21}$.

Los elementos míticos del viaje se adensan conforme avanza la acción: el Argos, tras navegar por sendas jamás surcadas antes («que no anduvieron / humanas plantas», vv. 183-184) arriba a una isla bárbara, que los recibe con una tormenta convocada mágicamente por el rey de Tinieblas, y en cuyo ámbito radica un jardín (trasunto del Paraíso) en el que los toros de bronce y dragones, dominados por una maga (Medea), guardan el árbol del que pende el vellocino (objeto maravilloso) que el héroe ha de conquistar venciendo todos los peligros.

Otro de los grandes viajes míticos, el de Ulises en su regreso a Ítaca después de la guerra de Troya, da el argumento para Los encantos de la Culpa, auto analizado por Aurora Egido en su prólogo a la edición de Escudero $^{22}$.

Como sucede con otros mitos, el viaje de Ulises y su aventura en la isla de la maga Circe, fue interpretado en clave moralizada. Circe es símbolo de la tentación, la mujer malvada y lasciva que incita al pecado y a los vicios, los cuales transforman a los hombres en bestias. A propósito de Ulises, recuerda Egido ${ }^{23}$ :

Encarnación de la elocuencia y de la sabiduría, el héroe se perfila como emblema de Cristo en numerosos textos, aunque ya Quevedo se quejaba en la Perinola de que Pérez de Montalbán se hubiese atrevido en su Polifemo (1632) a semejante símil, arguyendo «que los propios gentiles idólatras le llamaron engañador».

Pérez de Moya glosa la figura de Ulises como emblema de la vida del hombre, que debe hacer frente a tentaciones y casos de fortuna, o de la parte racional del hombre, obstaculizada por los apetitos ${ }^{24}$. En ese camino de la vida, el mar simboliza de nuevo al mundo, con sus tormentas amenazantes que ponen en peligro la nave del héroe:

ENTENDIMIENTO En la anchurosa plaza del mar del mundo hoy, Hombre, te amenaza gran tormenta. (vv. 1-3)

La tormenta y las aguas vuelven a simbolizar las tribulaciones, como ya se ha visto en citas anteriores:

${ }^{21}$ Ver notas al texto y el estudio preliminar de la edición citada para este globo cristalino y sus representaciones iconográficas.

${ }^{22}$ EGIDO, A. Introducción a Calderón de la Barca, P. Los encantos de la Culpa. Escudero, Juan Manuel (ed.). Pamplona / Kassel: Universidad de Navarra / Reichenberger, 2004.

${ }^{23}$ Ibidem, Introducción a Calderón de la Barca..., pp. 12-13.

${ }^{24}$ Ibidem, Introducción a Calderón de la Barca..., pp. 14-15. 
En el texto sagrado)

cuantas veces las aguas se han nombrado, tantos doctos varones

las suelen traducir tribulaciones. (vv. 25-28)

El lenguaje técnico marinero, muy frecuente en estos pasajes, comunica el dinamismo del viaje y la cercanía del naufragio, función habitual en los relatos del género:

Ó́DO
ENTENDIMIENTO
TACTO
OLFATO
GUSTO
Ó́DO
VISTA

El paralelo de la historia de Ulises y la del Hombre se hace cada vez más nítido conforme se desarrollan los episodios de la aventura odiseica:

Determinado el simbolismo del mar, el Hombre mismo elige su alegoría: «Ulises me he nombrado / que en griego decir quiere / cauteloso» (vv. 33-34). «Viador», navegante y peregrino, mostrará al espectador el curso de sus tribulaciones. Claro que con la ayuda del cielo, el mar se tranquiliza al principio y al final de la obra; primero para arribar al puerto de Circe - la prueba-, y después para llegar al puerto de salvación. [...] La idea del Homo viator (vv. 105-106), [...] se extiende metafóricamente al mar y a la tierra; de ahí la doble condición del hombre, navegante y peregrino, en busca de puerto seguro. La nave se perfila además hacia el final con el simbolismo tradicional de ser «la Iglesia soberana» (v. 1258), que acoge en ella a los hombres y los lleva a buen puerto ${ }^{25}$.

La aventura reitera elementos característicos de los viajes fabulosos, ya advertidos en otras ocasiones: la isla misteriosa («¿Qué tierra es esta? —No sé», v. 120), sucesos extraordinarios que ocurren en ella como las músicas que se oyen, las metamorfosis en bestias de los marineros de Ulises (los cinco sentidos), jardines deliciosos de cuyo suelo brotan mesas cubiertas de manjares, la aparición maravillosa de un palacio, al que llegan los exploradores para ser recibidos por hermosas mujeres, etc.; baste un ejemplo de la descripción que hace el Entendimiento, único salvado de la transformación animal:

\footnotetext{
${ }^{25}$ Ibidem, Introducción a Calderón de la Barca..., p. 46.
} 


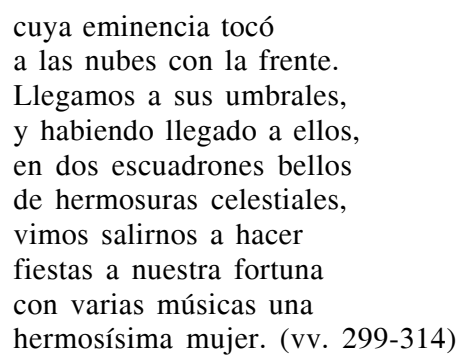

En ese palacio encantado caen presos los sentidos del Hombre/Ulises hasta que con la ayuda de Penitencia y Entendimiento consigan recobrar su forma humana (Ulises recobre la razón) y abandonen la isla funesta en la nave, ahora nave de la Iglesia, contrastada inútilmente por el viento del norte, e impulsada por el austro rumbo al puerto de Ostia ${ }^{26}$, con juego alusivo con el topónimo, que se repite en más autos de Calderón:

\begin{tabular}{|c|c|}
\hline TODOS & Dentro. ¡Buen viaje, buen viaje! \\
\hline Culpa & Aquesas voces me matan. \\
\hline HOMBRE & $\begin{array}{l}\text { Circe cruel, pues que supe } \\
\text { vencer prodigiosas magias, } \\
\text { quédate donde te sirva de monumento tu alcázar. }\end{array}$ \\
\hline Culpa & $\begin{array}{l}\text { Ondas, que tanto bajel } \\
\text { sufrís sobre las espaldas, } \\
\text { en vuestros senos de nieve } \\
\text { le dad sepulcro de plata. }\end{array}$ \\
\hline PENITENCIA & $\begin{array}{l}\text { Ondas, serenad el blando } \\
\text { movimiento de las aguas, } \\
\text { porque vuestros pavimentos } \\
\text { no sean montes sino alcázar. }\end{array}$ \\
\hline CULPA & $\begin{array}{l}\text { Vientos, que sopláis del norte. } \\
\text { no le saquéis de Tinacria, } \\
\text { y chocad, cascado el pino, } \\
\text { en aquellas peñas altas. }\end{array}$ \\
\hline PENITENCIA & $\begin{array}{l}\text { Notos, que venís del Austro, } \\
\text { soplad con suaves auras, } \\
\text { porque hasta el puerto de Ostia } \\
\text { hoy a salvamento salga. }\end{array}$ \\
\hline ENTENDIMIENTO & $\begin{array}{l}\text { Buen viaje nos prometen } \\
\text { las señas de la bonanza. }\end{array}$ \\
\hline CULPA & $\begin{array}{l}\text { Haced, vicios, que el velamen } \\
\text { todo pedazos se haga, } \\
\text { y vuelto el barco, sea tumba } \\
\text { con pirámides y jarcias. }\end{array}$ \\
\hline
\end{tabular}

\footnotetext{
${ }^{26}$ puerto de Ostia: puerto italiano en el Tíber, cerca de Roma; era el gran puerto que aseguraba en la antigüedad los suministros a Roma. El juego dilógico con 'hostia, sacramento' es obvio. Comp. La nave del mercader, vv. 1940-1942: «en cuyo duelo vencida / huyendo volví la espalda, / conque él pasó al puerto de Ostia».
} 
HOMBRE Haced, virtudes, que rompa

la quilla suave y blanda,

encrespando las espumas

TODOS vidrios de nieve y de plata. ¡Buen viaje, buen viaje, que vientos y ondas amainan!

(vv. 1288-1321)

Puede decirse, en conclusión, que el paradigma del viaje es nuclear en el género del auto sacramental, en cuanto todas las peripecias del Hombre, desde su caída en el pecado original y actual, hasta su salvación y llegada a la patria celestial, se conciben como una peregrinación en tierra extra$\tilde{n} a^{27}$, es decir, como un viaje lleno de obstáculos y peligros.

Estas piezas dramáticas presentan, bien en modo fragmentario, o más enterizo, algunos de los rasgos que Luis Alburquerque ${ }^{28}$ ha apuntado como definitorios de los relatos de viaje: motivo, itinerario, intención descriptiva. Más compleja es la utilización de la primera persona, —que requeriría ciertas matizaciones al aplicarse a personajes teatrales-, y sobre todo la elaboración de los aspectos de espacio y tiempo (cronología y lugares ${ }^{29}$ ) debido a la libertad omnímoda que el mecanismo alegórico permite. Como

${ }^{27}$ Comp. entre muchos otros textos San Pablo, Hebr., 11, 13: «quia peregrini et hospites sunt super terram»; 1 Pedro, 2, 11 «tamquam advenas et peregrinos abstinere vos a carnalibus desideriis»; San Agustín, ML, 37, col. 1884: el dolor del peregrino halla consuelo en la esperanza del regreso (a Dios): «Fideli homini et peregrino in saeculo nulla est jucundior recordatio quam civitatis [...] unde peregrinatur [...] sed non est sine dolore [...]. Spes tamen certa reditus nostri etiam peregrinando tristes consolatur [...] facit [Dios] ut cum illo simus, ascendere ad se»; San Pedro Damián, ML, 144, col. 456, exhorta al pecador a lograr una mansión celeste peregrinando: «peregrinando patriae sibi provideat mansionem»; San Bruno, ML, 152, col. 936, considera la desobediencia de los primeros padres causa de la doble peregrinación a que está sometido el hombre: una de apartamiento de Dios, antes de la muerte de Cristo y otra de regreso a Dios tras la Redención: «Erimus sicut dii [...] quod verbum fuit causa peregrinationis totius generis humani, et duplicis quidem peregrinationis [...] a domino [...] ante Christi mortem [...] alienabamur. Peregrinamur etiam [...] post redemptionem»; Pedro Lombardo, ML, 192, col. 39: mientras vivimos en el cuerpo peregrinamos lejos de Dios, aunque lo tengamos en la mente por fe: «dum sumus in hoc corpore mortali, peregrinamur a Domino, tamen in mente ipsum habentes per fidem»... Esta imagen del peregrino es omnipresente en los autos de Calderón, pero la trataré en otro momento, al analizar los viajes de peregrinación.

${ }^{28}$ ALBURQUERQUE GARCÍA, L. «A propósito de Judíos, Moros y Cristianos...», p. 505.

${ }^{29}$ Sobre todo en lo que respecta a las extensiones espaciales y disposición de los territorios que transitan los viajeros. Repetidamente los personajes justifican el manejo de espacio y tiempo de los autos apelando a la libertad alegórica: «en fantásticos cuerpos / de alegóricas figuras / no se da lugar ni tiempo» (El indulto general) o «Sí haré; y pues aquí nos vemos, / ser representable idea / de alegórico concepto / en quien retóricos tropos / no dan ni lugar ni tiempo; / volvamos atrás los siglos» (No hay instante sin milagro). Ver ARELLANO, I. Estructuras dramáticas y alegóricas en los autos de Calderón. Pamplona / Kassel: Universidad de Navarra / Reichenberger, 2001, p. 118. 
subrayan algunos de estos viajeros de los autos, sus itinerarios no se hallan sujetos a requisitos habituales de lugar y tiempo, pero esta circunstancia no aparece de modo relevante en los autos mitológicos que he tratado, de manera que remito su comentario a los análisis de otras modalidades de viaje en los autos calderonianos ${ }^{30}$.

En el grupo de autos que he observado aquí, los episodios de la acción se configuran - parcial o totalmente - sobre la base de argumentos mitológicos que tienen por esquema estructural precisamente el viaje: la expedición de los argonautas o el regreso de Ulises son casos especialmente privilegiados. Junto con las restantes modalidades, que estudio en otros lugares (peregrinaciones propiamente dichas, viajes misionales o vicisitudes de los desterrados, exiliados y fugitivos), el viaje mítico y épico, leído siempre a la luz del mecanismo alegórico, permite a Calderón insertar el atractivo de la aventura en la doctrina sacramental y trazar la historia de la salvación según el diseño de un viaje maravilloso: el que lleva al hombre desde el Paraíso terrenal, perdido por su pecado, al Paraíso celestial, conquistado con el libre albedrío y la ayuda de la gracia.

\section{REFERENCIAS BIBLIOGRÁFICAS}

ALBURQUERQUE GARCÍA, Luis. «A propósito de Judíos, Moros y Cristianos: El género relato de viajes en Camilo José Cela». Revista de Literatura, 66.132, 2004, pp. 503-524.

—. «Consideraciones acerca del género «relato de viajes» en la literatura del Siglo de Oro». En: El Siglo de Oro en el nuevo milenio, I. Pamplona: EUNSA, 2005, pp. 129-142.

- «Los libros de viaje como género literario». En: Diez estudios sobre literatura de viajes. Madrid: CSIC, 2006, pp. 67-87.

—. «Algunas notas sobre la consolidación de los relatos de viaje como género literario». En: Ars bene docendi. Homenaje al profesor Kurt Spang. Pamplona: EUNSA, 2009, pp. 27-34.

—. «Of travels and travellers: History of a literary genre». En: East and West. Exploring cultural Manifestations. New Delhi / Mumbai: Somaiya Publications, 2010, pp. 201-216.

ARELlANO, Ignacio. Diccionario de los autos sacramentales de Calderón. Kassel: Reichenberger, 2000.

- Estructuras dramáticas y alegóricas en los autos de Calderón. Pamplona / Kassel: Universidad de Navarra / Reichenberger, 2001.

CALDERÓN DE LA BARCA, Pedro. Andrómeda y Perseo. Ruano de la Haza, José M. (ed.). Pamplona/Kassel: Universidad de Navarra/Reichenberger, 1995.

-. El divino Jasón. Arellano, Ignacio y Ángel Cilveti (ed.). Pamplona / Kassel: Universidad de Navarra/ Reichenberger, 1992.

-. El divino Orfeo. Duarte, Enrique (ed.). Pamplona / Kassel: Universidad de Navarra / Reichenberger, 1999.

—. La nave del mercader. Arellano, Ignacio (ed.). Pamplona / Kassel: Universidad de Navarra / Reichenberger, 1996.

${ }^{30}$ Ver mis artículos, en prensa, «El motivo del viaje en los autos sacramentales de Calderón, II. Viajes misionales»; «El motivo del viaje en los autos sacramentales de Calderón, III. Los desterrados»; «El motivo del viaje en los autos sacramentales de Calderón, IV. Peregrinaciones». 
-. Los encantos de la Culpa. Escudero, Juan Manuel (ed.). Pamplona / Kassel: Universidad de Navarra / Reichenberger, 2004.

—. Obras completas, Autos. Valbuena Prat, Ángel (ed.). Vol. III. Madrid: Aguilar, 1987.

CARRIZO RUEDA, Sofía M. «Existe el género 'relatos de viajes’?». En: Caminería hispánica: Actas del II Congreso internacional de caminería hispánica: III. Caminería literaria e hispanoamericana. Madrid: AACHE, 1996a, pp. 39-44.

—. «Morfología y variantes del relato de viajes». En: Libros de viaje. Murcia: Universidad de Murcia, 1996b, pp. 119-126.

—. Poética del relato de viajes. Kassel: Reichenberger, 1997.

-. «Construcción y recepción de fragmentos de mundo». En: Escrituras del viaje. Buenos Aire: Biblos, 2008, pp. 9-34.

COVARRUBIAS, Sebastián de. Tesoro de la lengua castellana. Arellano, Ignacio y Zafra, Rafael (ed.). Madrid: Iberoamericana, 2006.

DANIÉLOU, Jean. Los símbolos cristianos primitivos. Munuera, C. (tr.). Bilbao: Ega, 1993.

Dictionnaire des antiquités grecques et romaines. Daremberg, Charles y Saglio, Edmond (dir.). Paris: Hachette, s. a.

DUARTE, Enrique (ed.). Introducción a Calderón de la Barca, P., El divino Orfeo. Pamplona / Kassel: Universidad de Navarra / Reichenberger, 1999.

EGIDO, Aurora. Introducción a Calderón de la Barca, P. Los encantos de la Culpa. Escudero, Juan manuel (ed.). Pamplona / Kassel: Universidad de Navarra / Reichenberger, 2004.

FERNÁNDEZ MOSQUERA, Santiago. La tormenta en el Siglo de Oro. Variaciones funcionales de un tópico. Madrid / Frankfurt am Main: Iberoamericana / Vervuert, 2006.

HENKEL, Arthur; SCHÖNE. Albrecht. Emblemata: Stuttgart, Metzler, 1976.

ML, Patrologia latina. Migne, con indicación de tomo y columna.

PÉREZ DE MOYA, J. Filosofía secreta, Gómez de Baquero, Eduardo (ed.). Madrid: Los clásicos olvidados, 1928.

POPEANGA, Eugenia. «El viaje iniciático: las peregrinaciones, itinerarios, guías y relatos». Revista de filología románica, Anejo 1, 1991, p. 27-371.

PRIETO, Melchor. Psalmodia eucarística. Madrid: Luis Sánchez, 1922, http://fondos digitales.us.es/fondos/libros/717/13/psalmodia-eucharistica [consulta: 5 de mayo 2011].

RAHNER, Karl. L'ecclesiologia dei Padri. Roma: Edizioni Paoline, 1971.

REGALÉS SERNA, Antonio. «Para una crítica de la categoría 'literatura de viajes'». Castilla, 5,1983 , pp. 63-85.

RUANO DE LA HAZA, José María. Introducción a Calderón de la Barca, P. Andrómeda y Perseo. Ruano de la Haza, J. M. (ed.). Pamplona / Kassel: Universidad de Navarra / Reichenberger, 1995.

RULL, Enrique. «Función teológico política de la loa». Notas y estudios filológicos. Pamplona: UNED, 2, 1985, pp. 33-46; y en Apuntes sobre la loa sacramental y cortesana. Loas completas de Bances Candamo. Arellano, Ignacio; Spang, Kurt y Pinillos, María Carmen (ed.). Kassel: Reichenberger, 1994, pp. 25-35.

—. «Hacia la delimitación de una teoría político-teológica en el teatro de Calderón». En: Calderón, Actas del Congreso Internacional sobre Calderón y el teatro español del Siglo de Oro. Luciano García Lorenzo (ed.). Madrid: CSIC, 1983, vol. II, pp. 759-767.

SUÁREZ, Ana. «El viaje marítimo del mercader en los autos de Calderón». Anuario calderoniano, 4, 2011 (en prensa).

WOLFZETTEL, Friedrich. «Relato de viaje y estructura mítica». En: Los libros de viaje: realidad vivida y género literario, Romero Tobar, Leonardo (ed.). Madrid: Akal, 2005, pp. $10-25$.

Fecha de recepción: 15 de abril de 2010

Fecha de aceptación: 16 de diciembre de 2010 